\title{
REVIEW
}

Open Access

\section{Socket seal surgery techniques in the esthetic zone: a systematic review with meta-analysis and trial sequential analysis of randomized clinical trials}

Andrea López-Pacheco ${ }^{1 *}$ (B), David Soto-Peñaloza², Mayra Gómez ${ }^{3}$, David Peñarrocha-Oltra ${ }^{2}$ and Marco Antonio Alarcón ${ }^{1}$

\begin{abstract}
Background: The socket seal surgery (SSS) technique is a common alternative for the management of the postextraction sockets that requires a primary closure of the wound to promote proper regeneration and ridge preservation.

Objective: To learn about the effect of different SSS techniques on alveolar ridge preservation

Material and methods: Two independent and calibrated reviewers conducted an electronic search in PubMed, Cochrane, and Web of Science for randomized clinical trials (RCT) published up to June 2020. The evaluation of the risk of bias in the included studies was carried out following the Cochrane manual for interventions of systematic reviews, version 5.1.0. A meta-analysis of ridge width changes at $-1,-3$, and $-5 \mathrm{~mm}$ cutoff points from bone crest was conducted using a random-effects model. The risk of types I and II errors against accrued data was appraised obtaining the required information size using a trial sequential analysis package (TSA).

Results: A total of 135 sockets located in the esthetic zone were evaluated with a minimum of a 3-month followup after tooth extraction in 6 RCTs. The evaluated SSS techniques were free gingival graft (FGG), collagen matrix $(C M)$, collagen sponge (CS), acellular dermal matrix (ADM), and polytetrafluoroethylene membrane (PTFEm). The FGG in sockets without bone filling showed significant results in preserving both buccal and lingual bone height $(-1.42 \mathrm{~mm}$ in the experimental group versus -0.01 in the control group). The comparison of CM and FGG with bone filling did not show clinical differences in terms of dimensional bone changes. No clinical differences were found in either width or gingival thickness when comparing CM and CS. The meta-analyses of RW changes comparing CM versus FGG showed no significant differences, but a trend for lessening horizontal reduction at -1 , -3 , and $-5 \mathrm{~mm}$ in favor of FGG. The TSA showed that accrued data did not reach the required information size, and more evidence is required for clinical significance inferences.

(Continued on next page)
\end{abstract}

\footnotetext{
* Correspondence: andrea.lopez.p@upch.pe

'Periolmplant Research Group UPCH, Academic Department of Clinical

Stomatology, Cayetano Heredia Peruvian University, Lima, Peru

Full list of author information is available at the end of the article
}

\section{Springer Open}

(ㅇ The Author(s). 2021 Open Access This article is licensed under a Creative Commons Attribution 4.0 International License, which permits use, sharing, adaptation, distribution and reproduction in any medium or format, as long as you give appropriate credit to the original author(s) and the source, provide a link to the Creative Commons licence, and indicate if changes were made. The images or other third party material in this article are included in the article's Creative Commons licence, unless indicated otherwise in a credit line to the material. If material is not included in the article's Creative Commons licence and your intended use is not permitted by statutory regulation or exceeds the permitted use, you will need to obtain permission directly from the copyright holder. To view a copy of this licence, visit http://creativecommons.org/licenses/by/4.0/. 
(Continued from previous page)

Conclusions: There are several predictable SSS techniques to improve clinical results in ridge preservation. More clinical studies in the form of clinical trials are required to demonstrate the superiority of one technique over another.

Keywords: Tooth socket, Humans, Tooth extraction, Alveolar ridge augmentation

\section{Introduction}

The esthetics in oral rehabilitation with dental implants represents a challenge in meeting the expectations and satisfaction of patients [1-3]. Many techniques seek to reduce bone resorption and subsequent soft tissue contour after dental extraction [4, 5], such as guided bone regeneration, connective tissue graft, and socket shield technique, among others. Guided bone regeneration performed to preserve the alveolar ridge usually requires a primary closure of the wound to promote proper regeneration and avoid contamination of the grafts $[6,7]$. It involves making incisions and lifting a flap that may reduce the blood supply, and cause a marginal recession at the adjacent teeth, defective papillae, loss of keratinized mucosa, increased postoperative pain, and swelling in patients [7-9]. These may have more impact on the anterior maxilla, where the anatomic features such as the labial plate are usually thinner and the esthetic outcomes are challenging.

An alternative for the management of postextraction sockets is "socket seal surgery" (SSS). This technique was first described by Landsberg and Bichacho [10]. It can be defined as a procedure that, through soft tissue grafts or biomaterials, can seal the socket, complementing the guided bone regeneration or acting alone to preserve the soft tissues, thereby preventing its collapse [11].

The SSS has achieved favorable results in various clinical studies [11-15], reaching values of more than 50\% graft integration after 6 weeks [12]; it further achieves a pleasing and esthetically acceptable color [13]. This technique begins taking a circular-shape epithelial tissue graft from the palate, usually with a punch, of a diameter similar to the alveolus to be sealed. The thickness of the epithelial graft is on average $2 \mathrm{~mm}$ [14]. The graft is sutured carefully with 6 to 10 stitches (ideally 6-0 gauge) [14]. It is recommended that, before suturing, the edge of the socket epithelium is revived to achieve adequate adaptation and vascularization of the graft. Although it is a predictable technique, some authors experienced partial or total necrosis of the graft $[11,15]$.

Currently, alternative materials to the palate graft are used, such as the collagen matrix $(\mathrm{CM})$, which avoids a second surgical area, reduces postoperative morbidity, and has satisfactory results in terms of esthetics and less scarring [16]. Likewise, other materials reported in the literature are collagen sponge (CS) [17], collagen membrane $[18,19]$, acellular dermal matrix (ADM) [20], and polytetrafluoroethylene membrane (PTFEm) [21], also reporting satisfactory results.

To our knowledge, this is the first review to focus solely on the effect of SSS on alveolar ridge preservation (ARP). This systematic review aims to evaluate radiographic and clinical dimensional changes of SSS techniques intended to preserve the alveolar ridge in postextractive sockets.

\section{Material and methods \\ Development of a protocol and registration}

This systematic review was registered in the PROSPERO database under number CRD42018094314 and was written following the PRISMA (Preferred Reporting Items for Systematic Reviews and Meta-Analyses) statement [22]. AMSTAR 2 checklist was followed to ensure the quality and transparency of the search [23].

\section{Focused question}

What is the effect of different socket seal surgery techniques on alveolar ridge preservation in the esthetic zone?

\section{Study population, type of intervention and comparisons,} and outcome measurements

Only RCTs were included in the analysis. PICO elements were used for ordinate reporting of information [24].

\section{Population}

Healthy individuals over 18 years old who had undergone any type of ARP and SSS following permanent single root tooth extraction in the maxilla. The minimum follow-up time was 3 months.

\section{Intervention}

Studies reporting on ARP including socket-sealing techniques.

\section{Comparison}

All possible comparisons among the included SSS materials were considered as long as the compared techniques had the same bone filler. 


\section{Outcome}

Studies reporting at least one of the following measurement methods:

Primary outcome: alveolar ridge width (RW) changes in millimeters at different cutoffs from the alveolar bone crest.

Secondary outcome: alveolar ridge height of the buccal plate $(\mathrm{RH})$ changes in millimeters and clinical changes in soft tissues.

\section{Search strategy}

The search strategy involves both electronic and manual searches. Electronic searches were performed in three databases: The National Library of Medicine (MEDLINE via PubMed), the Cochrane Central Register of Controlled Trials (CENTRAL), and Web of Science. The search strategy included terms related to the intervention and used the following combinations of keywords: (((()((tooth extraction) OR socket) OR tooth removal) OR alveoli)) OR immediate placement) OR postextraction) $)$ AND $(((()(((($ free gingival punch graft) OR free gingival graft) OR porcine collagen matrix) OR autogenous soft tissue graft) OR socket seal) OR collagen matrix seal) OR collagen sponge) OR subepithelial connective tissue)) AND ((( tooth extraction) OR socket) OR tooth removal) OR alveoli)). The results were limited to human studies. Also, an electronic screening of grey literature through Literature Report [25] and OpenGrey databases [26], as well as the consulting of references list of included studies, was conducted to detect potential eligible titles. The following journals were also screened up to June 2020: Clinical Oral Implants Research, Clinical Implant Dentistry and Related Research, European Journal of Oral Implantology, Implant Dentistry, International Journal of Oral and Maxillofacial Implants, International Journal of Periodontics and Restorative Dentistry, Journal of Clinical Periodontology, Journal of Dental Research, Journal of Oral and Maxillofacial Surgery, Journal of Periodontology. A manual search was also made in the bibliographies of the articles included. Only articles in English were included.

\section{Eligibility criteria for study inclusion/exclusion Inclusion criteria}

- Studies on humans

- Patients needing a single root tooth extraction between maxillary premolars, who had undergone any type of ARP with SSS

- Flapless extraction

- Reporting at least one of the following measurement methods: clinical measurement, three-dimensional radiographic evaluation, or histological examination

- Randomized controlled trials

\section{Exclusion criteria}

- Studies on medically compromised patients (e.g., systemic diseases)

- General contraindications to implant surgery: untreated periodontitis, severe bruxism or clenching, immunosuppression, previous history of irradiation of the head and neck area, uncontrolled diabetes, heavy smoker (> 10 cigarettes/day), poor oral hygiene and motivation, current or past treatment with bisphosphonates, substance abuse (alcohol, drugs), psychiatric disorders.

- Socket sealing with a coronally advanced flap

- Studies using different bone filling materials per group

- Studies that compare alveolar ridge preservation techniques with bone graft versus spontaneous healing.

- Studies with the inability to complete the follow-up.

\section{Screening methods and data extraction}

It was conducted independently and in duplicate by two reviewers (A.L.P and M.G). According to selection criteria, titles and abstracts of search results were screened, and potential articles, or those with insufficient data to make a clear decision, were analyzed in full text for the eligibility criteria. Disagreements are resolved by discussion and consultation with a third author (M.A.A). The reasons for exclusion at this or subsequent stages were recorded. The level of agreement between reviewers against title eligibility was done using kappa scores (Cohen's $\mathrm{k}$ coefficient) and interpreted according to Landis and Koch scale [27].

The following data are extracted in predefined Excel spreadsheets by two authors (A.L.P, M.G) and considering: author, year, country, reporting of a priori sample size estimation, sample size (sites), socket seal surgery approach, type of bone graft material, socket integrity, method of dimension measurement, follow-up, radiographic and clinical outcome measurements (alveolar ridge width, alveolar ridge height of the buccal plate, and buccal gingival thickness), study setting, and funding sources. The data extraction was ascertained for adequacy by a third author (M.A.A); disagreements were solved by consensus.

\section{Quality assessment}

Assessment of the risk of bias was carried out by two reviewers (A.L.P, MG) independently. The assessment was carried out in duplicate and based on guidance from a modification of the Cochrane tool [28] used to evaluate the methodological quality of the included studies.

The following six parameters-random sequence generation, allocation concealment, blinding of participants 
and personnel, blinding of outcome assessment, incomplete outcome data, and selective reporting-were evaluated as low risk, moderate risk, or high risk of bias.

\section{Data analysis and synthesis of the results}

Statistical data handling was performed by one author (D.S.P.). Random-effects meta-analysis is conducted for the primary outcome (ridge width changes) with at least 6 months follow-up after SSS. Forest plots were created to illustrate the effects of the meta-analysis results. The effect size between test and control groups are summarized as mean difference (MD) in millimeters, and its respective $95 \%$ confidence intervals $(\mathrm{CI})$.

Because the results of ridge preservation procedures might be affected by either clinical (e.g., age, sex, surgery, clinical expertise) and methodological aspects inherent to clinical trials conduction, a Sidik-Jonkman (Hartung-Knapp-Sidik-Jonkman) random effects model is carried out because it provides adequate type I error rates [29]. This approach is more robust to changes in the heterogeneity variance estimates, especially in metaanalyses that contain few studies [30]. Between-study heterogeneity was visually inspected in the forest plots and by calculating the $\mathrm{\tau} 2$ (absolute heterogeneity) and the $I^{2}$ statistics (relative heterogeneity), and the corresponding nullity statistical $Q$ test was calculated. The $I^{2}$ index defines the proportion of total variability in the result explained by heterogeneity, but no chance. Heterogeneity was roughly categorized as low, moderate, and high to $I^{2}$ values of $25 \%, 50 \%$, and $75 \%$ [31]. Publication bias was investigated by visual inspection of the funnel plot and employing the Egger test only if at least 10 studies are included. In the case of high heterogeneity, a sensitivity analysis is conducted to test the robustness of estimates excluding risk populations or effect modifiers. A two-sided level of significance of $5 \%(\alpha=0.05)$ was established. The Stata/SE version 16.1 for Mac (StataCorp LP, College Station, TX, USA) was used for quantitative synthesis.

\section{Additional analysis}

The meta-analytic output is tested for the propensity of type I (false positives) and type II (false genitives) statistical errors and to analyze the power of available evidence using the Trial Sequential Analysis (TSA) openaccess software (Trial Sequential Analysis v0.9 $\beta$, Copenhagen Trial Unit, Center for Clinical Intervention Research, Denmark). A type 1 error of $5 \%$ and a power of $80 \%$ (type 2 error $=80 \%$ ) were set to calculate trial sequential monitoring boundaries, futility boundaries, and the required information size (RIS). A "model variance-based" approach is defined for the inconsistency correction and $I^{2}$ values established according to meta-analytic data output if the heterogeneity observed is zero; a lower inconsistency $\left(I^{2}=25 \%\right)$ is assumed for RIS estimation based on a random-effects model as previously reported [32]. The anticipated mean difference between intervention groups is setting for an expected minimal biological plausible difference (lower bound of 95\% CI) of $-0.18,-0.33$, and $-0.38 \mathrm{~mm}$ between DBBM and DBBM-C, for horizontal ridge preservation at 1,3 , and $5 \mathrm{~mm}$ from the bone crest [33]. A graphical evaluation was performed to determine whether the $Z$ curve (showing the treatment effect) crossed either monitoring or futility boundaries and to obtain the RIS threshold.

\section{Results}

Data collection

The initial search found a total of 741 records in the electronic and manual searches. After removal of duplicates and the title and abstract screening, a total of 14 articles remained for full-text assessment (Fig. 1). Six studies were finally included for qualitative analysis [34-39] and two for quantitative analysis [35, 37]. The reviewers showed an almost perfect level of agreement $(k=0.92)$. The most common reason for exclusion was those studies that compare different bone filling materials per group. The excluded papers and the reasons for exclusion are listed in Table 1, and the main characteristics of the included studies are summarized in Table 2.

\section{Characteristics of included studies Study design and population}

A total of 135 sockets in the esthetic zone were evaluated in 6 RCTs. Five studies presented a parallel design $[34,35,37-39]$, and one presented a split mouth design [36]. Only two studies perform an a priori power calculation $[37,38]$. The study population ranged from 18 to 30 individuals.

\section{Type of intervention and biomaterials}

A flapless extraction approach was performed in all studies. Different techniques were described for SSS: FGG [35-37, 39], CM [35, 37-39], CS [38], ADM [34], and PTFEm [32]. In three of the included studies, bone xenografts were the material chosen [35, 37, 39], two studies used bone allografts [34, 38], and only one study did not use any bone graft material [36].

\section{Methods of measurement}

Changes in the primary outcomes were assessed by clinical and radiographic examinations. Bone changes in width and height were examined in four studies using CBCT [35-38]. Clinical measurement was reported in three studies [34, 38, 39]; one study evaluated the ridge width using digital models [39]; one study recorded the 


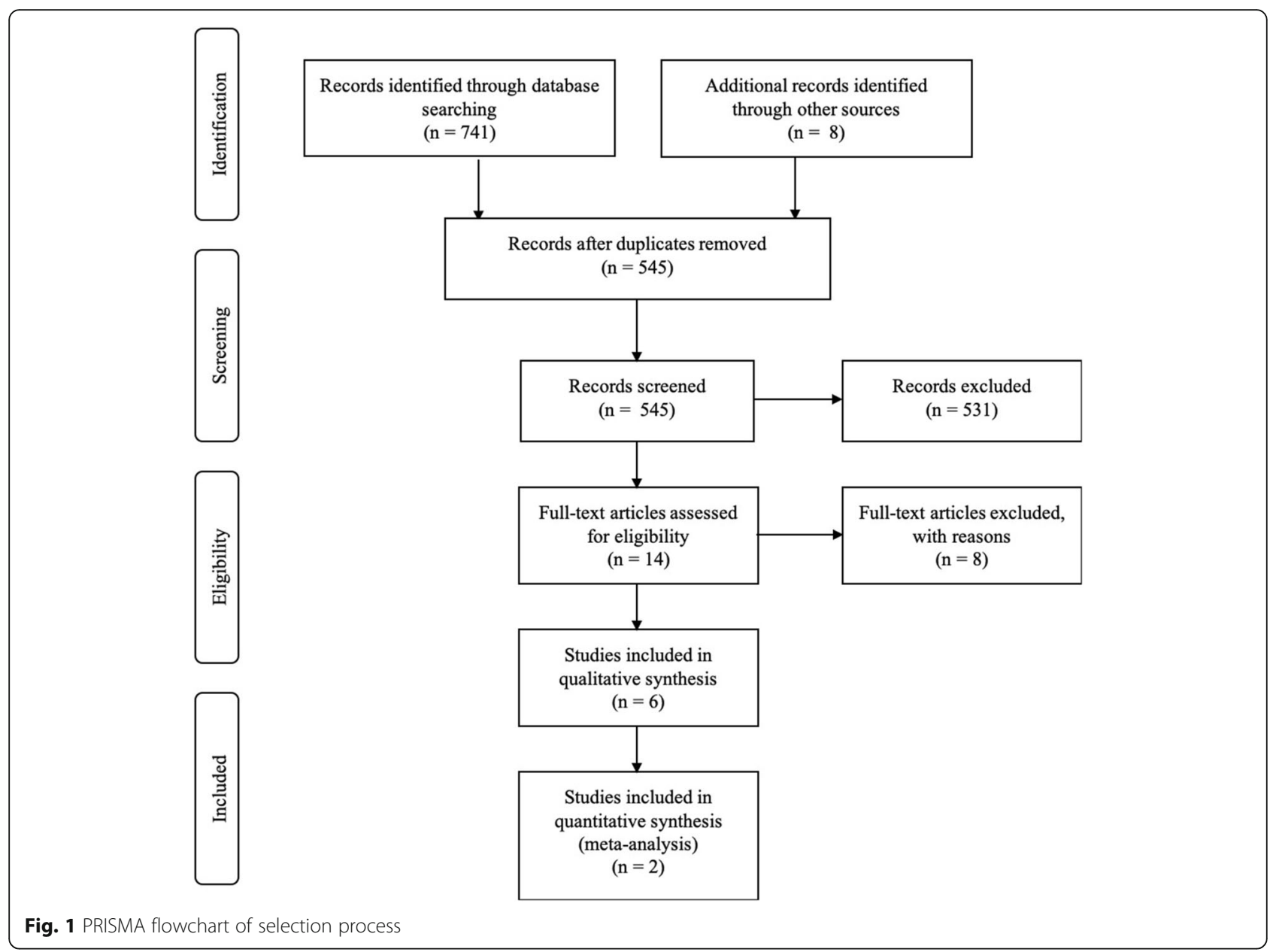

Table 1 Studies excluded with reasons

\begin{tabular}{|c|c|c|c|}
\hline Author & Year & Title & Reason for exclusion \\
\hline $\begin{array}{l}\text { Araujo and } \\
\text { Lindhe [4] }\end{array}$ & 2015 & $\begin{array}{l}\text { Ridge alterations following grafting of fresh extraction sockets in man. A } \\
\text { randomized clinical trial. }\end{array}$ & $\begin{array}{l}\text { Compare alveolar ridge preservation with } \\
\text { bone graft versus spontaneous healing }\end{array}$ \\
\hline $\begin{array}{l}\text { Ávila-Ortiz } \\
\text { et al. }\end{array}$ & 2020 & Efficacy of alveolar ridge preservation: a randomized controlled trial & $\begin{array}{l}\text { Compare alveolar ridge preservation with } \\
\text { bone graft versus spontaneous healing }\end{array}$ \\
\hline $\begin{array}{l}\text { Cardaropoli } \\
\text { et al. [5] }\end{array}$ & 2012 & $\begin{array}{l}\text { Socket preservation using bovine bone mineral and collagen membrane: a } \\
\text { randomized controlled clinical trial with histologic analysis }\end{array}$ & $\begin{array}{l}\text { Compare alveolar ridge preservation with } \\
\text { bone graft versus spontaneous healing }\end{array}$ \\
\hline Hu et al. & 2009 & $\begin{array}{l}\text { Clinical study of tissue preservation of extraction socket with bio-oss collagen } \\
\text { and acellular dermal matrix. }\end{array}$ & $\begin{array}{l}\text { Compare alveolar ridge preservation with } \\
\text { bone graft versus spontaneous healing }\end{array}$ \\
\hline Neiva et al. & 2011 & $\begin{array}{l}\text { Analysis of tissue neogenesis in extraction sockets treated with guided bone } \\
\text { regeneration: clinical, histologic, and micro-CT. }\end{array}$ & Socket sealing with coronally advanced flap. \\
\hline Oghli et al. & 2010 & $\begin{array}{l}\text { Ridge preservation following tooth extraction: a comparison between } \\
\text { atraumatic extraction and socket seal surgery. }\end{array}$ & Compare different bone filler per group \\
\hline Park et al. & 2016 & $\begin{array}{l}\text { The hidden } \mathrm{X} \text { suture: a technical note on a novel suture technique for } \\
\text { alveolar ridge preservation }\end{array}$ & Includes molar area \\
\hline $\begin{array}{l}\text { Sadatmansouri } \\
\text { et al. }\end{array}$ & 2013 & $\begin{array}{l}\text { Comparison of dPTFE and FGG for socket bone augmentation: a clinical and } \\
\text { histological study }\end{array}$ & Different language \\
\hline $\begin{array}{l}\text { Thalmair et al. } \\
\text { [40] }\end{array}$ & 2013 & $\begin{array}{l}\text { Dimensional alterations of extraction sites after different alveolar ridge } \\
\text { preservation techniques - a volumetric study. }\end{array}$ & Compare different bone filler per group \\
\hline
\end{tabular}




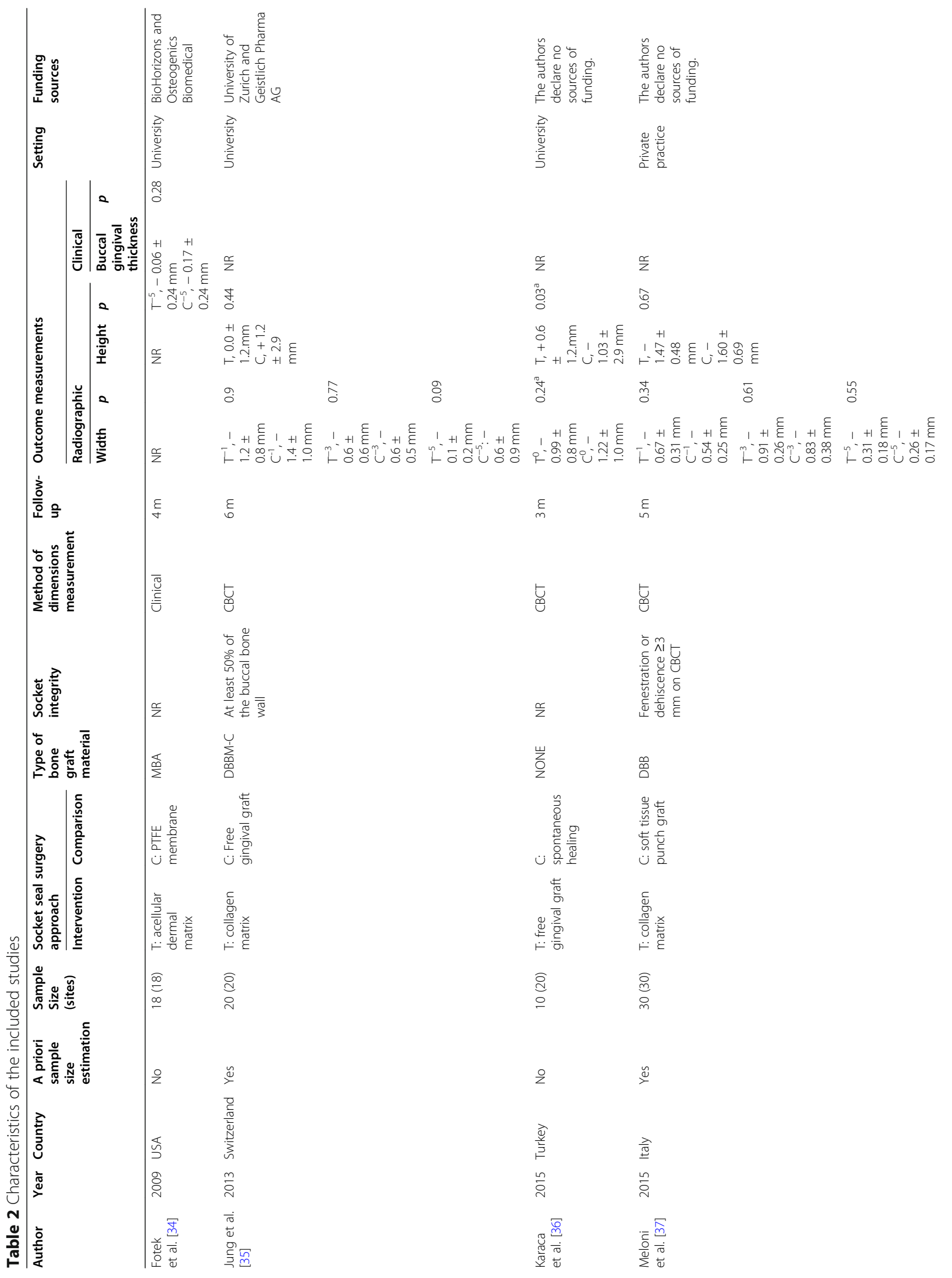


López-Pacheco et al. International Journal of Implant Dentistry

(2021) 7:13

Page 7 of 14

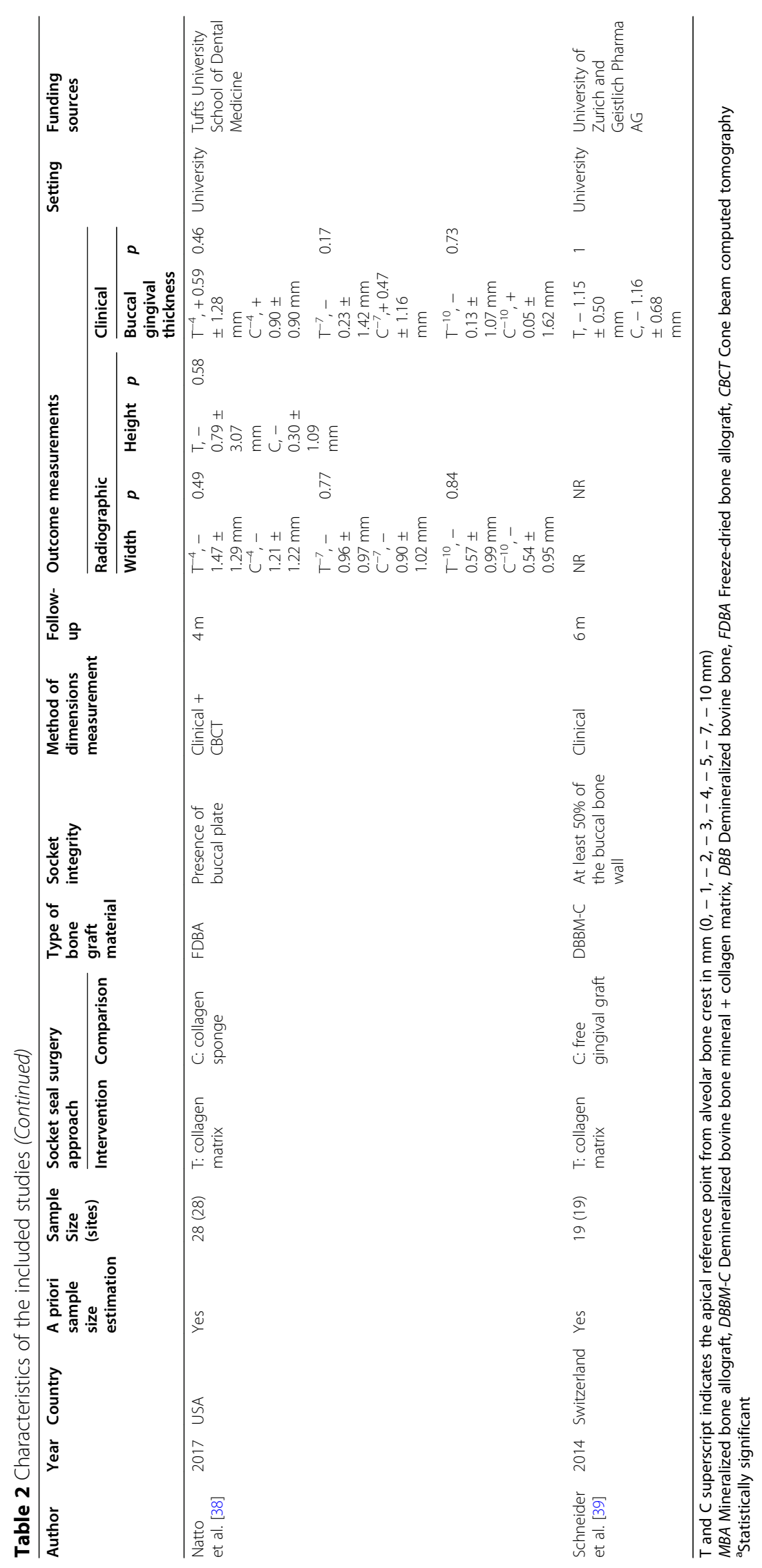


soft tissue thickness using stents [34]. Moreover, only one study registers the width of keratinized tissue band at the baseline and the endpoint of the investigation [38].

\section{Qualitative synthesis of study outcomes}

The height of the buccal and lingual crest was analyzed in a split-mouth study [36] comparing sockets that had healed spontaneously with those treated with FGG without additional bone graft. After 3 months of healing, the control sockets had lost height in the buccal crestal bone - $1.42 \mathrm{~mm}$; however, the height in the buccal crestal bone was preserved at the test sites $-0.01 \mathrm{~mm}$. This difference between the two groups was statistically significant $(p \leq 0.05)$. In contrast, both the control and test groups lost width in the buccal and lingual crestal bone; the difference between the control and test groups was not statistically significant $(p \geq 0.05)$.

Socket seal surgery using FGG or CM was compared by CBCT analysis in two studies [35, 37]. After 5 [37] and 6 months [35], they found width changes at $1 \mathrm{~mm}$ below the crest, between -0.54 and $-1.4 \mathrm{~mm}$ respectively, for sockets sealed with FGG, and -0.67 and -1.2 $\mathrm{mm}$ respectively in sockets sealed with a CM. This difference between the two groups was not statistically significant $(p>0.05)$.

Natto et al. [38] evaluated the results of CM seal in similar hard and soft tissue remodeling compared to that with CS used as barriers at 4 months following ARP, in combination with freeze-dried bone allograft. They found that reduction in coronal ridge width $(-1.21 \mathrm{~mm}$ $\mathrm{CM}$ and $-1.47 \mathrm{~mm} \mathrm{CS}$ ) and vertical buccal bone resorption $(-0.30 \mathrm{~mm}$ CMS and $-0.79 \mathrm{~mm} \mathrm{CS}$ ) was not statistically significant. A slight increase in buccal gingival thickness at the coronal part was observed in both groups ( $0.9 \mathrm{~mm} \mathrm{CM}$ and $0.5 \mathrm{~mm} \mathrm{CS})$. The width of keratinized tissue decreased by an average of $0.08 \mathrm{~mm}$ in both groups.

The use of resorbable and non-resorbable membranes in ARP was compared by Fotek et al. [34]. The PTFEm exfoliated prematurely by 28 days, whereas the ADM appeared to be incorporated into the tissues. After 4 months, they found ridge width changes between -0.06 $\pm 0.24 \mathrm{~mm}$ for sockets sealed with ADM and $-0.17 \pm$ $0.24 \mathrm{~mm}$ in sockets sealed with a PTFEm. No statistically significant difference was observed between the two treatment modalities $(p=0.280)$.

\section{Risk of bias of included studies}

Blinding of participants and personnel was not comprehensively reported, resulting in an unclear risk of bias for these domains in all studies. However, random sequence generation, allocation concealment, attrition, and reporting were of less concern in most studies (Fig. 2).

\section{Quantitative summary-meta-analysis}

Meta-analysis was able only for the primary outcome of the review. Only 2 studies allow a statistical comparison for RW reduction at $-1,-3$, and $-5 \mathrm{~mm}$ from bone crest after 6 months of socket sealing surgery [35, 37]. The results of meta-analyses are depicted visually throughout forest plots (Fig. 3). It was observed that mean differences of RW reduction did not reach statistical significance among data subsets $(p \geq 0.05)$. The horizontal bone reduction tended to be more accentuated within collagen matrix group at $1 \mathrm{~mm}(\mathrm{MD}-0.09$; 95\% CI [- 0.37; 0.19]; $\left.I^{2}=13 \%\right)$ and $3 \mathrm{~mm}(\mathrm{MD}-0.06$; 95\% CI $[-0.28 ; 0.15] ; I^{2}=0 \%$ ) cutoff points from alveolar bone crest (Fig. 3a, b). These findings occur in a context of low heterogeneity. The analysis at $5 \mathrm{~mm}$ from

\begin{tabular}{|c|c|c|c|c|c|c|c|}
\hline & 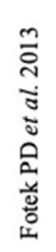 & 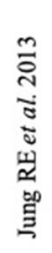 & 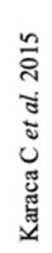 & 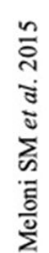 & 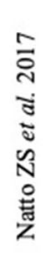 & 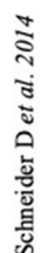 & \\
\hline \multicolumn{8}{|l|}{ Random sequence generation (selection bias) } \\
\hline Allocation concealment (selection bias) & ) & 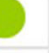 & 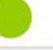 & 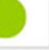 & 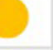 & ) & Low risk of bias \\
\hline Blinding of participants and personnel (performance of bias) & 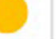 & 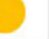 & & 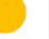 & ) & 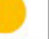 & Unclear risk of bias \\
\hline Blinding of outcome assesement (detection bias) & 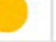 & 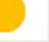 & & 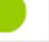 & ) & 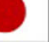 & High risk of bias \\
\hline Incomplete outcome data (attition bias) & 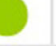 & ) & 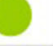 & 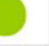 & D & 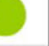 & \\
\hline Selective reporting (reporting bias) & 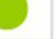 & 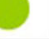 & 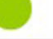 & 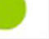 & J & 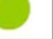 & \\
\hline
\end{tabular}




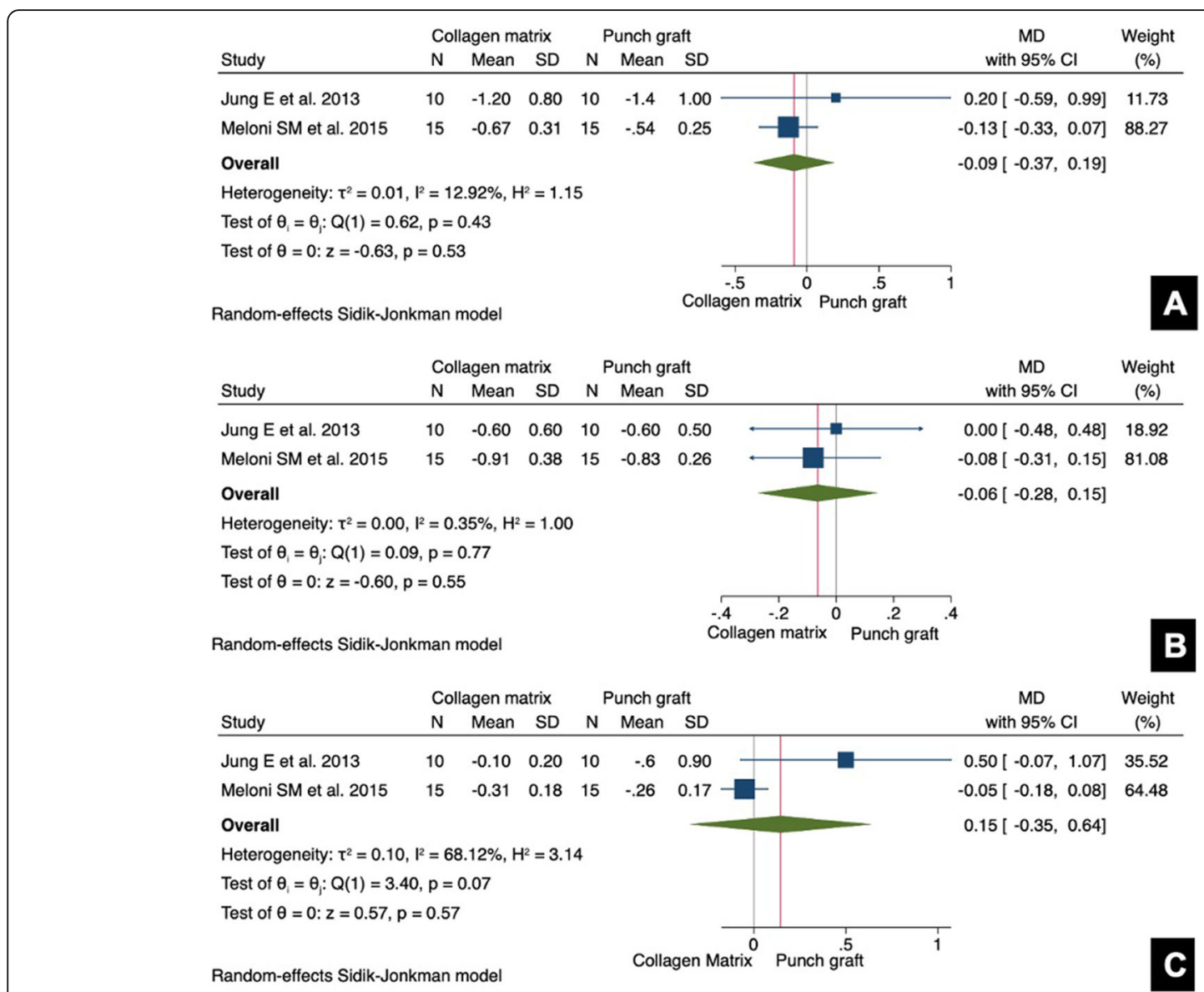

Fig. 3 Forest plots of meta-analyses evaluating alveolar ridge width changes at different cutoff points from the alveolar bone crest. a RW at - 1 $\mathrm{mm}$. b RW at $-3 \mathrm{~mm}$. c RW at $-5 \mathrm{~mm}$

bone crest showed an increase of RW dimension in favor of FGG group (MD 0.15; 95\% CI $[-0.35 ; 0.64] ; I^{2}=$ $68 \%$ ), but in a context of high heterogeneity. Egger's test for publication bias is not applicable due to the lack of information ( $\leq 10$ studies); indeed, it is visually explored using funnel plots, which showed a slight asymmetry. Though, these observations must be considered as merely exploratory and interpreted with caution (Additional file 1).

\section{Results of TSA}

It was observed how the $z$ curve does not cross the statistical significance threshold (brown lines) nor the monitoring boundaries' (red lines). A sample of 297 grafted sites (individuals) is required for an anticipated horizontal ridge width reduction of $-0.33 \mathrm{~mm}$ at $3 \mathrm{~mm}$, for an alpha error $(0.05 \%)$, and power $(1$-beta $=0.20 \%)$ in a two-tailed statistical test. This required information size is adjusted, assuming a low heterogeneity $\left(I^{2}=25 \%\right)$ because the observed inconsistency in this meta-analysis was zero. The RIS obtained surpassed the accrued data in the present meta-analysis (Fig. 4b).
The RIS was estimated for the ridge width reduction at -1 and $-5 \mathrm{~mm}$ from the bone crest. The RIS estimation was set according to anticipated mean differences as mentioned above, and it was observed that accrued meta-analytical data for RW reduction was not reached (Fig. 4b, c). Thus, more studies are warranted to determine which alveolar socket seal technique provides better results on ridge preservation, due to the sparse data available to make clinical significance inferences.

\section{Discussion}

The present work aimed to assess the socket-sealing surgery techniques intended to preserve the alveolar ridge in post-extractive sockets. To date, despite being a routine clinical procedure, there are few qualified RCTs available to evaluate the effect of different SSS techniques for ARP. After literature screening, six studies were included in qualitative synthesis, from which only two RCTs [35, 37] allowed its statistical comparison for ridge width reduction at 6 months, and considering different cutoffs points $(-1,-3$, and $-5 \mathrm{~mm})$ from the bone crest. The SSS techniques found in this systematic 

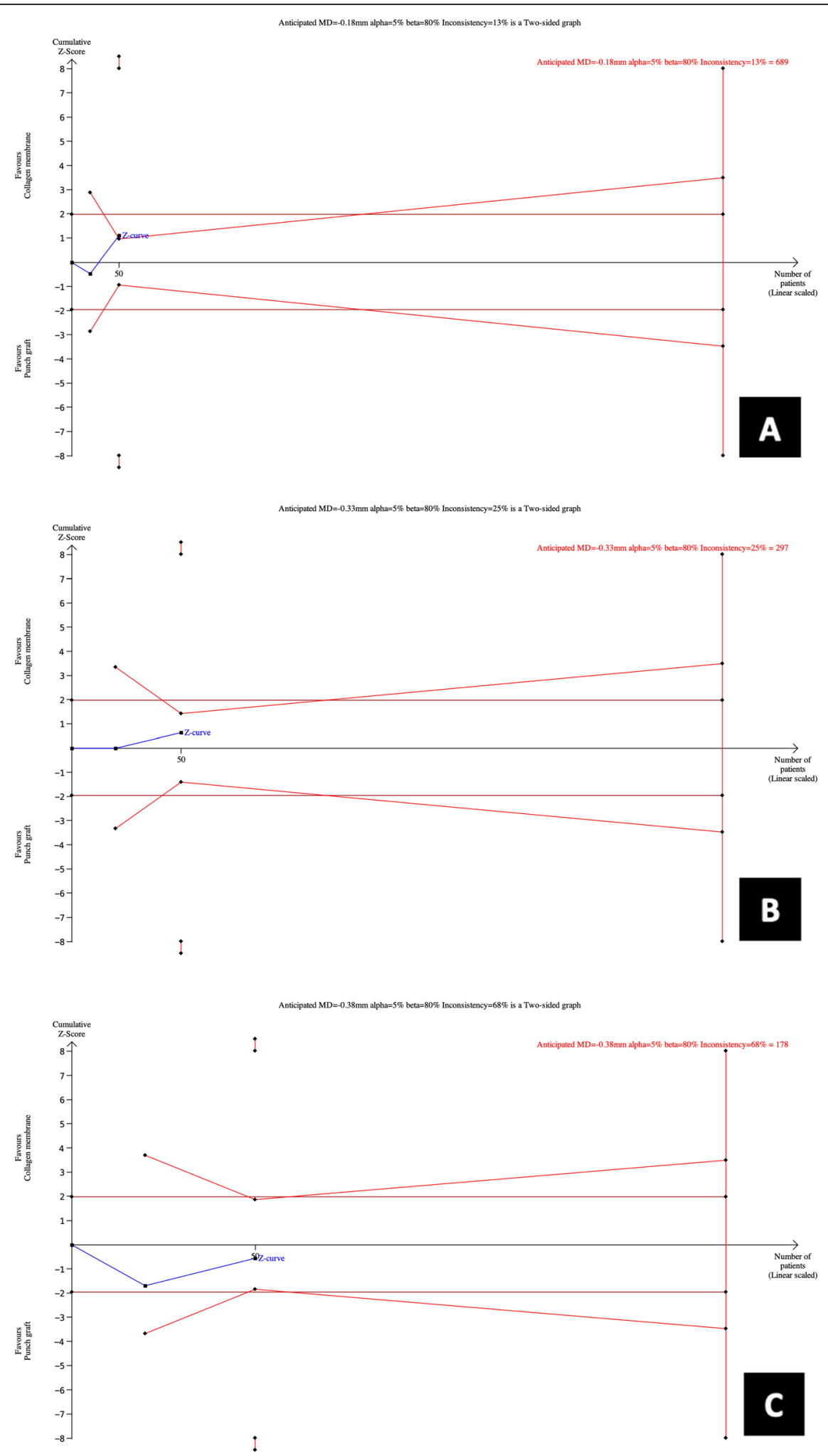

Fig. 4 Trial sequential analysis for required information size estimations. a RW $-1 \mathrm{~mm}$. b RW - 3. c RW - $5 \mathrm{~mm}$ 
review were described as FGG, CM, CS, ADM, and PTFEm providing effective results in the esthetic zone [34-39].

Regarding methodological quality, most studies showed a parallel arm design [34, 35, 37-39], except a study with split-mouth approach [36]. The most critical methodological concerns are related to the blinding of participants and personnel. Note to mention, blinding of participants in surgical trials are challenging to perform, and evidence suggests that bias associated with lack of blinding and lack of concealment may be higher in trials with subjective outcomes [41].

In short, this review showed that the SSS techniques enhance the ARP outcomes at both alveolar bone dimensional changes. Notwithstanding, if the goal is to evaluate the effect of SSS techniques, the need for homogeneity in the bone filler is imperative, thus eliminating bias when comparing the superiority of one material against another.

In keeping with this observation, data extraction is made seeking comparability between studies; a fact allowing a meta-analytic approach to assessing the dimensional changes on RW between CM and FGG groups at different cutoffs points of the alveolar bone crest.

Meta-analyses results did not show significant statistical differences $(p \geq 0.05)$, but a trend for slight dimensional changes on the ridge width in the CM group at 1 and -3 mm cutoffs, with mean differences of -0.09 $\mathrm{mm}$ and $-0.06 \mathrm{~mm}$ respectively. These findings suggest that use of FGG as socket-sealing material may lessen the alveolar ridge width loss. Moreover, at $5 \mathrm{~mm}$ from the bone crest, the differences showed a slight RW gain of $0.15 \mathrm{~mm}$ favoring FGG sealing material (Fig. 5). The adequacy for accrued data on meta-evidence was tested for the propensity of type I and type II errors, which often occurs in trials with small sample size, as metaanalysis including few studies with sparse sample size.

After conducting the TSA, it was concluded that the required information size to accept or reject the null hypothesis is far from the available meta-evidence on the study topic up to date. Thus, more studies are warranted to determine which socket-sealing surgery is better for its implementation.

\section{Agreements and disagreements with previous literature}

To our knowledge, this is the first systematic review focused on specifically evaluating the different SSS techniques. The use of FGG as SSS can have the benefit of preserving the height of the buccal bone following tooth extraction according to the study of Karaca et al. [36]. Sockets with spontaneous healing had lost height in the buccal bone $(-1.42 \mathrm{~mm})$ after 3 months; conversely, the height was preserved at sockets using SSS without bone filling $(-0.01 \mathrm{~mm})$. This seems to be an adequate alternative for those cases in which the buccal table is greater than $1 \mathrm{~mm}$, and the use of bone filling may not be imperative [42].

Additional benefits of SSS are the effects on soft tissue conditions by maintaining and increasing the keratinized tissue using FGG or CM. Three studies compared the two techniques $[35,37,39]$ and found them to be effective and predictable for preserving the alveolar dimensions and attaining a band of keratinized tissue which at the same time affords benefits on peri-implant health $[43,44]$. Nevertheless, the use of a CM reduces the risk of necrosis in the FGG. No significant differences were found between the two groups; however, CM was associated with a significantly lower patient morbidity [45], avoiding graft donor site involvement. Patient comfort

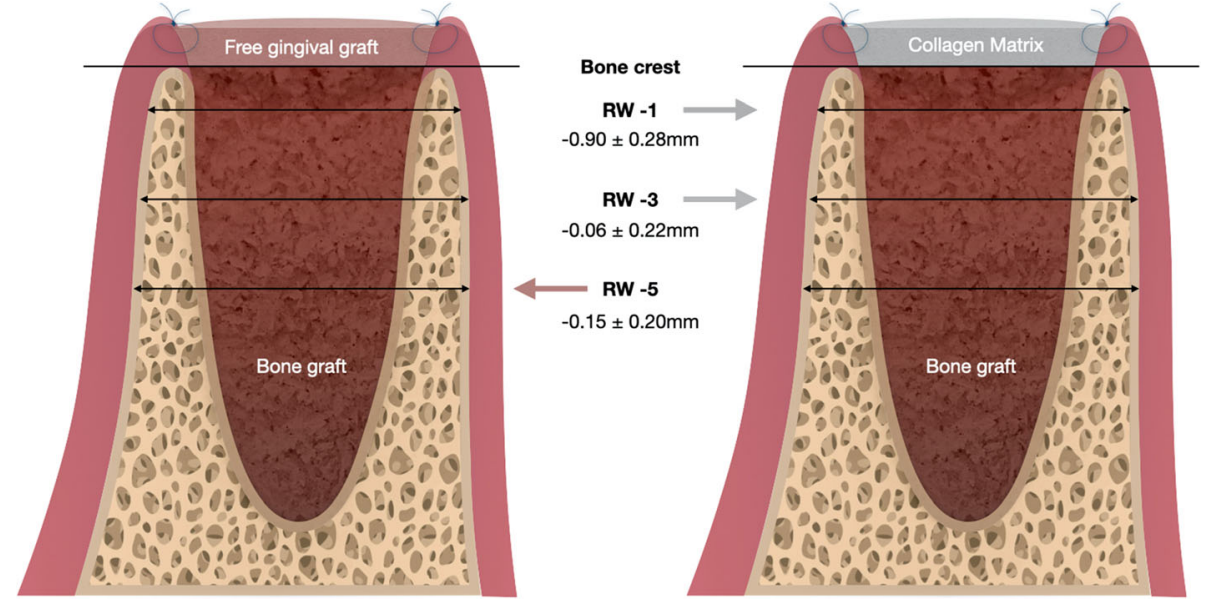

Fig. 5 Meta-analytic illustration shows a trend for slight dimensional changes on the ridge width (RW) in the collagen matrix group at - 1 and $3 \mathrm{~mm}$ cutoffs and a slight RW gain of $0.15 \mathrm{~mm}$ favoring free gingival graft sealing material 
should be an important factor in considering the appropriate treatment alternative for the patient [46].

Since ARP is incapable of entirely avoiding the alveolar ridge reduction [5], SSS surgery procedures may optimize esthetic results by limiting the postoperative external contour shrinkage [14]. Schneider et al. [39] evaluated the horizontal volume change in sockets with ARP and SSS as compared with unassisted sockets clinically. Six months after the extraction, they found a reduction on dimensional changes of the buccal contour when performing ARP with the use of FGG or CM as SSS. These results are consistent with Thalmair et al. [40], in which they determined that regardless of the use of bone, soft tissue cover minimizes the contraction of the buccal contour.

The use of CS material was suggested not only to protect the graft materials but also to induce blood clot formation and to stabilize the wound [47]. Collagen dressing materials are preferable due to their inherent properties. The material is a hemostatic agent and possesses the ability to stimulate platelet aggregation and enhance fibrin linkage, which may lead to initial clot formation, stability, and maturation [48]. A limited number of studies evaluated this technique in combination with ARP [17, 37, 49-51]. One included study compared it to the use of CM seal and indicated that CS could form an effective barrier for the bone graft in ARP procedures [37]. They found a reduction in coronal ridge width, vertical buccal bone resorption, and a slight increase in buccal gingival thickness compared to $\mathrm{CM}$. The width of keratinized tissue decreased by an average of $0.08 \mathrm{~mm}$ in both groups, which shows minimal loss of tissue. The use of CS could be an alternative; however, despite the benefits, these results should be viewed with caution, due to the small number of patients and studies using this alternative.

Even though, most articles recommend the use of absorbable materials for socket seal; intentionally exposed PTFE membrane at post-extraction sites can predictably lead to an increase of keratinized tissue [52] and the preservation of gingival architecture [21]. Although PTFEm is exposed to the oral cavity, they are not permeable to bacteria. Histological data showed that directly after the removal of the membrane there were no endothelial cells or bacterial contamination, on the contrary, initial granulation tissue was found, so PTFE membranes do not seem to interrupt the healing process of the newly formed tissue [53]. However, despite the benefits, the results of the study by Fotek et al. [34] did not find a statistically significant difference when comparing the width of the keratinized tissue and the thickness of the soft tissue compared to an ADM.

Additional techniques have been found on the literature as the ice cream cone technique using a collagen membrane for socket seal $[18,19]$, the use of PRF as a socket plug [54], or a saddle connective tissue graft [55]. Although these are also techniques commonly used in clinical practice and according to the previously mentioned studies show favorable results, to date, we have not found randomized clinical trials that, according to our inclusion criteria, allow us to add in these or other techniques in this study.

\section{Efforts and limitations in the review process}

The efforts of the present work rely on the comprehensive literature search, the implementation of critical appraisal of literature methodology and the implementation of quantitative synthesis methods to reduce the propensity of type I error, as the use of a "trial sequential analysis" to determine the adequacy of information size.

Due to seeking the best quality of studies and avoiding bias, only randomized clinical trials were included in this study. Note to mention, the need to find studies comparing SS materials based on the same bone filler between groups had a significant impact on the number of included studies. However, it is important to highlight the importance of this criterion, since having homologous comparative groups will allow us to objectively evaluate the effects of socket seal, which is the main objective of this study.

Among the limitations, the variety of materials, the small number of participants per group, the lack of long-term data, and the lack of homogeneity in particulate bone grafts between studies, are sources of clinical and methodological heterogeneity. Moreover, the sparse data on meta-analysis increased the risk of infraestimating or overestimating the effect size and variance of interventions.

\section{Generality of the review results and future research}

A slight trend for lessening the ridge width loss is observed in favor of the FGG approach, but based on sparse data that did not meet the required information size after a sequential trial analysis. This systematic review supports that socket sealing surgery is a technique that can afford benefits than conventional approaches for alveolar preservation. For this reason, its importance should be underscored, to promote further investigations to enhance the body of the evidence, allowing clinicians the draw of evidence-based reliable recommendations.

\section{Conclusions}

Based on the results of this systematic review, there are several effective SSS techniques to improve the clinical results in the preservation of the alveolar ridge and lessen bone resorption. More clinical studies are required to demonstrate the superiority of one technique over another. 


\section{Supplementary Information}

The online version contains supplementary material available at https://doi. org/10.1186/s40729-021-00294-2.

\section{Additional file 1: Appendix S1}

\section{Abbreviations}

SSS: Socket seal surgery; ARP: Alveolar ridge preservation; RCT: Randomized clinical trials; FGG: Free gingival graft; CM: Collagen matrix; CS: Collagen sponge; ADM: Acellular dermal matrix; PTFEm: Polytetrafluoroethylene membrane; RW: Alveolar ridge width; RH: Alveolar ridge height; RIS: Required information size; TSA: Trial sequential analysis package; MD: Mean difference; $\mathrm{Cl}$ : Confidence intervals

\section{Acknowledgements}

Not applicable.

\section{Authors' contributions}

Dr. Marco Alarcón and Dr. Andrea López-Pacheco conceived and planned the subject of the systematic review. Dr. Andrea López-Pacheco and Dr. Mayra Gómez performed the search strategy, article analysis, and quality assessment of the included articles. Disagreements were resolved by discussion with Dr. Marco Antonio Alarcón that along with Dr. David Peñarrocha-Oltra formed an active part of the systematic review in the revision and correction of the article. Dr. Andrea López-Pacheco and Dr. David Soto-Peñaloza has made the tables and figures and contributed to the writing of the article. Dr. David Soto-Peñaloza and Dr. David Peñarrocha-Oltra performed the statistical data and contributed to the interpretation of the results. All colleagues mentioned took part in the development of this article. All authors read and approved the final manuscript.

\section{Funding}

Not applicable.

\section{Availability of data and materials}

Not applicable.

\section{Ethics approval and consent to participate}

Not applicable.

\section{Consent for publication}

Not applicable.

\section{Competing interests}

Andrea López-Pacheco, David Soto-Peñaloza, Mayra Gómez, David Peñarrocha-Oltra, and Marco Antonio Alarcón declare that they have no competing interest.

\section{Author details}

${ }^{1}$ Periolmplant Research Group UPCH, Academic Department of Clinical Stomatology, Cayetano Heredia Peruvian University, Lima, Peru. ${ }^{2}$ Oral Surgery Unit, Department of Stomatology, Valencia University Medical and Dental School, Valencia, Spain. ${ }^{3}$ Academic Department of Clinical Stomatology, Section of Oral Implantology, Cayetano Heredia Peruvian University, Lima, Peru.

Received: 6 September 2020 Accepted: 25 January 2021

Published online: 22 February 2021

\section{References}

1. Cardaropoli D, Cardaropoli G. Preservation of the postextraction alveolar ridge: a clinical and histologic study. Int J Periodontics Restor Dent. 2008; 28(5):469-77.

2. Schropp L, Wenzel A, Kostopoulos L, Karring T. Bone healing and soft tissue contour changes following single-tooth extraction: a clinical and radiographic 12-month prospective study. Int J Periodontics Restor Dent. 2003;23:313-23.

3. Tarnow D, Eskow R, Zamzok J. Aesthetics and implant dentistry. Periodontol 2000. 1996;11:85-94
4. Araujo $M G$, Lindhe J. Ridge alterations following tooth extraction with and without flap elevation: an experimental study in the dog. Clin Oral Implants Res. 2009;20:545-9.

5. Cardaropoli D, Tamagnone L, Roffredo A, Gaveglio L, Cardaropoli G. Socket preservation using bovine bone mineral and collagen membrane: a randomized controlled clinical trial with histologic analysis. Int J Periodontics Restorative Dent. 2012;32:421-30.

6. Wang HL, Boyapati L. "PASS" principles for predictable bone regeneration. Implant Dent. 2006;15(1):8-17.

7. Wang HL, Kiyonobu K, Neiva RF. Socket augmentation: rationale and technique. Implant Dent. 2004;13:286-96.

8. Fickl S, Zuhr O, Wachtel H, Bolz W, Huerzeler M. Tissue alterations after tooth extraction with and without surgical trauma: a volumetric study in the beagle dog. J Clin Periodontol. 2008;35(4):356-63.

9. Fickl S, Kebschull M, Schupbach P, Zuhr O, Schlagenhauf U, Hurzeler MB Bone loss after full-thickness and partial-thickness flap elevation. J Clin Periodontol. 2011;38:157-62.

10. Landsberg CJ, Bichacho N. A modified surgical/prosthetic approach for optimal single implant supported crown. Part l--the socket seal surgery. Pract Periodontics Aesthet Dent. 1994;6(2):11-7.

11. Tal H. Autogenous masticatory mucosal grafts in extraction socket seal procedures: a comparison between sockets grafted with demineralized freeze-dried bone and deproteinized bovine mineral. Clin Oral Implants Res. 1999;10:289-96

12. Jung RE, Siegenthaler DW, Hämmerle $\mathrm{CH}$. Postextraction tissue management: a soft tissue punch technique. Int J Periodontics Restor Dent. 2004;24(6):545-53.

13. Misch CE, Dietsh-Misch F, Misch CM. A modified socket seal surgery with composite graft approach. J Oral Implantol. 1999;25(4):244-50.

14. Negri B, Zuhr O, Fickl S, Ciurana XR, Navarro Martínez JM, Blanco VM. Socket seal surgery: clinical uses in implant dentistry and guided bone regeneration procedures for single tooth replacement in the esthetic zone. Quintessence Int. 2016:47(2):123-39.

15. Tal H. Autogenous masticatory mucosal grafts in extraction socket seal procedures: a comparison between sockets grafted with demineralized freeze-dried bone and deproteinized bovine bone mineral. Clin Oral Implants Res. 1999;10(4):289-96.

16. Stimmelmayr M, Güth JF, Iglhaut G, Beuer F. Preservation of the ridge and sealing of the socket with a combination epithelialized and subepithelial connective tissue graft for management of defects in the buccal bone before insertion of implants: a case series. Br J Oral Maxillofac Surg. 2012; 50(6):550-5.

17. Kim YK, Yun PY, Lee HJ, Ahn JY, Kim SG. Ridge preservation of the molar extraction socket using collagen sponge and xenogeneic bone grafts. Implant Dent. 2011;20(4):267-72

18. Elian N, Cho SC, Froum S, Smith RB, Tarnow DP. A simplified socket classification and repair technique. Pract Proced Aesthet Dent. 2007;19(2): 99-104

19. Tan-Chu JH, Tuminelli FJ, Kurtz KS, Tarnow DP. Analysis of buccolingual dimensional changes of the extraction socket using the "ice cream cone" flapless grafting technique. Int J Periodontics Restor Dent. 2014;34(3):399_ 403.

20. Novaes AB Jr, Souza SL. Acellular dermal matrix graft as a membrane for guided bone regeneration: a case report. Implant Dent. 2001;10(3):192-6.

21. Bartee BK. Extraction site reconstruction for alveolar ridge preservation. Part 2: membrane-assisted surgical technique. J Oral Implantol. 2001;27(4):194-7.

22. Moher D, Liberati A, Tetzlaff J, Altman DG, PRISMA Group. Preferred reporting items for systematic reviews and meta- analyses: the PRISMA statement. Ann Intern Med. 2009;151:264-9.

23. Shea BJ, Reeves BC, Wells G, Thuku M, Hamel C, Moran J, Moher D, Tugwell P. Welch V, Kristjansson E, Henry DA. AMSTAR 2: a critical appraisal tool for systematic reviews that include randomized or non-randomized studies of healthcare interventions, or both. BMJ. 2017;358:j4008.

24. Schardt C, Adams MB, Owens T, Keitz S, Fontelo P. Utilization of the PICO framework to improve searching PubMed for clinical questions. BMC Med Inform Decis Mak. 2007:15:7-16.

25. Grey Literature Report. The New York Academy of Medicine. Available at: http://www.greylit.org. Accessed June 2020.

26. Open Grey. Avaiable at: http://www.opengrey.eu. Accessed June 2020.

27. Cohen J. A coefficient of agreement for nominal scales. Educ Psychol Meas. 1960;20(1):37-46. 
28. Higgins JP, Altman DG, Gøtzsche PC, et al. The Cochrane Collaboration's Tool for assessing risk of bias in randomised trials. BMJ. 2011;343:d5928.

29. IntHout J, loannidis JP, Borm GF. The Hartung-Knapp-Sidik-Jonkman method for random effects meta-analysis is straightforward and considerably outperforms the standard DerSimonian-Laird method. BMC Med Res Methodol. 2014;14:25.

30. Langan D, Higgins JPT, Jackson D, et al. A comparison of heterogeneity variance estimators in simulated random-effects meta-analyses. Res Synth Methods. 2019;10(1):83-98.

31. Higgins JP, Thompson SG. Quantifying heterogeneity in a meta-analysis. Stat Med. 2002;21(11):1539-58

32. Jakobsen JC, Wetterslev J, Winkel P, Lange T, Gluud C. Thresholds for statistical and clinical significance in systematic reviews with meta-analytic methods. BMC Med Res Methodol. 2014;14:120.

33. Llanos AH, Sapata VM, Jung RE, et al. Comparison between two bone substitutes for alveolar ridge preservation after tooth extraction: cone-beam computed tomography results of a non-inferiority randomized controlled trial. J Clin Periodontol. 2019;46(3):373-81.

34. Fotek PD, Neiva RF, Wang HL. Comparison of dermal matrix and polytetrafluoroethylene membrane for socket bone augmentation: a clinical and histologic study. J Periodontol. 2009;80(5):776-85.

35. Jung RE, Philipp A, Annen BM, Signorelli L, Thoma DS, Hämmerle CH, Attin $\mathrm{T}$, Schmidlin P. Radiographic evaluation of different techniques for ridge preservation after tooth extraction: a randomized controlled clinical trial. J Clin Periodontol. 2013;40(1):90-8.

36. Karaca Ç, Er N, Gülşahı A, Köseoğlu OT. Alveolar ridge preservation with a free gingival graft in the anterior maxilla: volumetric evaluation in a randomized clinical trial. Int J Oral Maxillofac Surg. 2015:44(6):774-80.

37. Meloni SM, Tallarico M, Lolli FM, Deledda A, Pisano M, Jovanovic SA Postextraction socket preservation using epithelial connective tissue graft vs porcine collagen matrix. 1-year results of a randomized controlled trial. Eur J Oral Implantol. 2015:8(1):39-48.

38. Natto ZS, Parashis A, Steffensen B, Ganguly R, Finkelman MD, Jeong YN. Efficacy of collagen matrix seal and collagen sponge on ridge preservation in combination with bone allograft: a randomized controlled clinical trial. J Clin Periodontol. 2017:44(6):649-59.

39. Schneider D, Schmidlin PR, Philipp A, Annen BM, Ronay V, Hämmerle CH, Attin T, Jung RE. Labial soft tissue volume evaluation of different techniques for ridge preservation after tooth extraction: a randomized controlled clinical trial. J Clin Periodontol. 2014:41(6):612-7.

40. Thalmair T, Fickl S, Schneider D, Hinze M, Wachtel H. Dimensional alterations of extraction sites after different alveolar ridge preservation techniques - a volumetric study. J Clin Periodontol. 2013;40(7):721-7.

41. Wood L, Egger M, Gluud LL, et al. Empirical evidence of bias in treatment effect estimates in controlled trials with different interventions and outcomes: meta-epidemiological study. BMJ. 2008;336(7644):601-5.

42. Chappuis V, Engel O, Shahim K, Reyes M, Katsaros C, Buser D. Soft tissue alterations in esthetic postextraction sites: a 3-dimensional analysis. J Dent Res. 2015;94(9):187-93.

43. Lin GH, Chan HL, Wang HL. The significance of keratinized mucosa on implant health: a systematic review. J Periodontol. 2013;84(12):1755-67.

44. Giannobile WW, Jung RE, Schwarz F. Groups of the 2nd Osteology Foundation Consensus Meeting. Evidence-based knowledge on the aesthetics and maintenance of peri-implant soft tissues: Osteology Foundation Consensus Report Part 1-effects of soft tissue augmentation procedures on the maintenance of peri-implant soft tissue health. Clin Oral Implants Res. 2018;29(15):7-10.

45. Gargallo-Albiol J, Barootchi S, Tavelli L, Wang HL. Efficacy of xenogeneic collagen matrix to augment peri-implant soft tissue thickness compared to autogenous connective tissue graft: a systematic review and meta-analysis. Int J Oral Maxillofac Implants. 2019;34(5):1059-69.

46. Feine J, Abou-Ayash S, Al Mardini M, et al. Group 3 ITI Consensus Report: patient-reported outcome measures associated with implant dentistry. Clin Oral Implants Res. 2018;29(Suppl 16):270-5.

47. Santhosh K. Local hemostatic agents in the management of bleeding in oral surgery. Asian J Pharm Clin Res. 2016;9:35-41.

48. Ogle OE. Perioperative hemorrhage. In: Dym H, Ogle OE, editors. Atlas of minor oral surgery. Philadelphia, PA: W.B. Saunders; 2000. p. 62-3.

49. Wood RA, Mealey BL. Histologic comparison of healing after tooth extraction with ridge preservation using mineralized versus demineralized freeze-dried bone allograft. J Periodontol. 2012;83(3):329-36.
50. Spinato S, Galindo-Moreno P, Zaffe D, Bernardello F, Soardi CM. Is socket healing conditioned by buccal plate thickness? A clinical and histologic study 4 months after mineralized human bone allografting. Clin Oral Implants Res. 2014;25(2):120-6.

51. Eskow AJ, Mealey BL. Evaluation of healing following tooth extraction with ridge preservation using cortical versus cancellous freeze-dried bone allograft. J Periodontol. 2014;85(4):514-24.

52. Barboza EP, Stutz B, Mandarino D, Rodrigues DM, Ferreira VF. Evaluation of a dense polytetrafluoroethylene membrane to increase keratinized tissue: a randomized controlled clinical trial. Implant Dent. 2014;23(3):289-94.

53. Laurito $D$, Cugnetto $R$, Lollobrigida $M$, et al. Socket preservation with d-PTFE membrane: histologic analysis of the newly formed matrix at membrane removal. Int J Periodontics Restor Dent. 2016;36(6):877-83.

54. Girish Kumar N, Chaudhary R, Kumar I, Arora SS, Kumar N, Singh H. To assess the efficacy of socket plug technique using platelet rich fibrin with or without the use of bone substitute in alveolar ridge preservation: a prospective randomized controlled study. Oral Maxillofac Surg. 2018;22(2): 135-42.

55. Seyssens L, Eghbali A, Christiaens V, De Bruyckere T, Doornewaard R, Cosyn J. A one-year prospective study on alveolar ridge preservation using collagen-enriched deproteinized bovine bone mineral and saddle connective tissue graft: a cone beam computed tomography analysis. Clin Implant Dent Relat Res. 2019;21(5):853-61.

\section{Publisher's Note}

Springer Nature remains neutral with regard to jurisdictional claims in published maps and institutional affiliations.

\section{Submit your manuscript to a SpringerOpen ${ }^{\circ}$ journal and benefit from:}

- Convenient online submission

- Rigorous peer review

- Open access: articles freely available online

High visibility within the field

- Retaining the copyright to your article

Submit your next manuscript at $>$ springeropen.com 